\title{
FEATURES OF DEVELOPMENT OF SELF-REGULATION ABILITIES IN PEDAGOGICAL ACTIVITY OF SPORTS COACH
}

\author{
Mospan Marina ${ }^{1}$ \\ Kovalchuk Victoria ${ }^{2}$
}

DOI: dx.doi.org/10.30525/978-9934-571-30-5_10

\begin{abstract}
The article analyzes scientific ideas about the specifics of the content of sports and educational activities. The analysis of sports and pedagogical activities of the coach has shown that it is associated with a constant need to solve pedagogical assignments of different complexity, to conduct experiments; it also requires flexibility and autonomy in decision-making; constant search for new methods of work; the constant enhancement of creative abilities to achieve certain goals. It has been established that successful coaching activity depends on the presence of a constant professional self-improvement of the coach's personality, the acquisition of new experience and knowledge, the development of the ability to see the prospect of the development of athletes, since these elements of professional development affect the result of all the pedagogical activities of the trainer. It was also investigated that the results of the coach's work are also largely influenced by his ability to predict, correct and control the behavior of athletes in the process of achieving the goal. Taking to consideration above mentioned the future teacher should be emotionally restrained, able to control himself, which means a high level of self-regulation and mental resilience. The problem of self-regulation of mental resilience is primarily connected with the research of mental states management processes and the preservation of the mental health of the personality of teaching coach. The purpose of the research - is studying the psychological characteristics of professional pedagogical activity of sports teachers on the basis of theoretical and empirical research, studying the peculiarities of the formation of the person's ability to self-regulation in pedagogical activity.
\end{abstract}

\footnotetext{
${ }^{1}$ Associate Professor of the Department of Psychology Pedagogy,

National University of Physical Education and Sports of Ukraine, Ukraine

${ }^{2}$ Associate Professor of the Department of Psychology,

National University of Physical Education and Sports of Ukraine, Ukraine
} 


\section{Introduction}

The activity of the coach is a two-way process of interaction between the trainer and athletes, where, on the one hand, the functions of the coach consist of a conscious influence on the students in order to regulate the relationships in the sports team, to form necessary skills in students, to construct certain goals, tasks and strategies, and on the other hand - the result of the effectiveness of implementation of these goals depends on the students feedback, or from their reaction on the coach's personality and behavior.

The success of this interaction depends on the matching of the personality traits of the coach, the presence of necessary features for a successful coaching activity. Currently, there is no clear idea about the psychological peculiarities of the self-regulation of the psychological states of teachers in pedagogical activity. Insufficient study of the peculiarities of changing mental conditions and the peculiarities of their self-regulation in pedagogical activities has determined the relevance of empirical research.

The purpose of the study - on the basis of theoretical and empirical study of the psychological characteristics of professional pedagogical activity of sports trainers to study the peculiarities of formation of the person's ability to self-regulation in pedagogical activities.

Planning current study, assuming that the level of self-regulation directly affects the effectiveness of educational activity. This relationship integrates the personal consistent dependence of the student's performance on the level of development of their intellectual, emotional-volitional, personal and professional qualities. The development and formation of self-regulation tools is one of the factors that determine the manifestation of patterns and trends in this extensive system of relationships.

\section{Athletic - pedagogical activity of the sports coach}

To comprehensively examine the characteristics of the activity of a sports trainer, first of all, it is necessary, to analyze scientific ideas about the specifics of the content of sports and pedagogical activity. According to this, Bandurka A.M., Bocherova S.P., Zemlyanska O.V. (1998) consider following functions as the main ones for the sports coach:

- administrative and organizational function - the coach coordinates and directs the individual actions of the students, according to their rights and responsibilities; 


\section{Mospan Marina, Kovalchuk Victoria}

- strategic - the coach indicates long-term and short-term goals, defines the means and methods for their achievement, and also efficiently adapts them, depending on the emergence of new tasks;

- planning - the coach determines specific tasks, stages and time frame for their implementation;

- expert-advisory functions - the trainer is the most authoritative qualified team member and the source of reliable information;

- communicative - the coach is the keeper of important information, which has the most significant role in the process of collective decision making;

- educational - the coach takes part in the formation and consolidation of the students qualities necessary for a successful sporting activity;

- psychotherapeutic - the trainer is the subject of regulation of the students psychological state in conflict or stressful situations, and also the coach affects the general psychological climate in the team;

- representative - the coach provides communication with the outside professional environment [1, p. 318].

As a result of synthesis and analysis of scientific works of well-known coaches, educators and psychologists, Zh.B. Berezhnaya (2013) suggested structure of vocational and pedagogical activity of trainers, which consists of five components:

1. Organizational component (goal setting, organization of sport activity management, modeling of own future activity and behavior).

2. Gnostic component (knowledge in the field of theory and practice of physical culture and sports, sports training, psychology, pedagogy, and the ability to apply this knowledge).

3. The personal component (professional skills of the coach and professionally important qualities).

4. Operational-active component (associated with the direct use of coaching activities).

5. The communicative component (the ability to organize a pedagogical interaction, the ability to create a comfortable psychological climate in the team, the ability to motivate, etc.) [2, p. 21].

Deminsky A.C. (2005) also indicated the importance of organization, planning, regulation, control and analysis among the general functions of sports coach in the long-term training process [3, p. 18]. From the proposed generalization, it can be seen that various scholars point out the presence of similar components in the structure of vocational and pedagogical 
activities of the coach. When preparing young athletes, V.I. Voronova and V. Nikolaenko (2014), based on the systematization and analysis of scientific works of the last decades, based on the features of the trainer's role as a educator, proposed a list of criteria that must be answered by coach for kids and juniors: to put the child's development above sporting results; to know the features and possibilities of each age group, to understand the individual and personal potential of each child, to respect children's rights; to adjust the pedagogical program taking into account the age characteristics of athletes; to be fair in relation to each child; to create a favorable atmosphere for the development of young athletes; to listen to the desires of children, to promote their independence and proactivness; to be an example for children in matters of moral and cultural behavior; to give preference to the game, not to the exercises; to use inductive method, which forms children's ability to analyze; to support the interest of children, making training more differentiated, progressive and varied; to combine patience, tolerance, and willingness to protect their students from the influence of other people who interfere into the training process [2, p. 27].

Understanding the role of the pedagogical component in the activities of the coach are expressed by Kedrovsky B.G., Shalar O.G., Grinevich A.V. (2013), arguing that the main function of the coach in the junior team is the involvement in the process of forming the athlete's personality, this process can be represented "as a functioning of a complex dynamic system, the interaction of which elements is due to the leading role and authority of the coach, the influence of the external environment, the state of the adolescent (athlete)" [4, p. 8].

The analysis of the sports and pedagogical activities of the coach showed that it is associated with the constant need to solve problems of various complexity; to experiment; requires flexibility and autonomy in decision making; constant search for new methods of work; the constant enhancement of creative abilities and creativity in order to achieve certain goals.

\section{Psychological components of the trainer's personality}

In sports and pedagogical literature, the psychological aspects of the professional activity of the coach remain unaltered.

B.C. Ogilvie (1982), established within his research the presence solid character of coach, resistance to mental stress, independence, being realistic and authoritarianistic [10, p. 176]. 


\section{Mospan Marina, Kovalchuk Victoria}

The results of the coach's activity are also largely influenced by his ability to predict, correct and control both his and athletes behavior in the process of achieving the goal.

Platonov V.N. (2005) argues that the athlete's and coach's interaction affects the psycho-emotional state of the athlete, which in turn is an important factor in success of his sports career. An important role of the coach, this scientist thinks that support of the athlete's interest in exercises is increased due to constant joint work, involvement of the athlete in the creative process of planning and implementation of the training process [7, p. 28].

As a result of the theoretical and empirical research Fedik O.P. (1999) systematized into four groups the most significant personality traits of sports coaches, necessary for successful professional activity. The first group of personality characteristics includes the attitude of the coach to athletes, including attentiveness, justice, delicacy, trust, adherence to principles, objectivity, politeness, tolerance, ability to reckon with the athlete's mind, willingness to help, humanity, honesty, responsibility, respect for athletes etc. Such qualities as adherence to principles and objectivity take a key position in the process of regulating the behavior of the coach in the interaction with athletes. At the same time, they reflect the general attitude of the coach to the organization of sports activity [15, p. 16].

The second group of qualities explains the particular attitude of athletes to the coach and includes communicative, democratic, attractive, authoritative, ability to listen.

The third group describes the characteristics of self-paced coach: modesty, self-confidence, demanding.

Last fourth group explains the features of the mental development of the coach, specifically the features of the volitional, emotional, intellectual and behavioral spheres.

Having analyzed the opinion of athletes Fedik O.P. concluded that the most important quality of coach students consider in the first (attitude of the coach to athletes) and the second group (cooperation of the coach with athletes). At the same time, coaches with experience of up to 5 years prefer the third (the attitude of the coach) and the fourth group (the mental development of the coach), and coaches with experience of more than 5 years - the second (the relationship of the coach with athletes) and the fourth group (mental development coach). 
According to Petrovskaya T.V. (2004), the coach has the central role in the organization of sports activity, where the main component is the person-oriented education and training of the coach. Understanding by the coach of socio-psychological foundations of the formation of relations, causes and methods for preventing the emergence of conflict situations contributes to increasing the effectiveness of the activities of the entire sports team.

Recent studies of the characteristics of the coach's work show that the higher the qualification of the coach is the more adequate his self-esteem, while coaches with a lower qualification tend to overestimate self-esteem of their activity.

Typically, the assessment of their own abilities is characteristic of trainers-teachers with a dominant external positive motivation of professional activity. Trainers and educators with the most significant internal motivation of professional activity are inclined to adequately assess their professional abilities, resulting in greater achievement in their activity.

Thus, the analysis of the connection between the formation of pedagogical skills, depending on the assessment of students and the dominant motivation of professional activity, makes it possible to predict the effectiveness of the coaching activity of novice specialists (Stepanchenko N.I., 2012) [13, p. 101].

\section{Methods and organization of research}

In order to obtain more detailed and objective data, as well as thorough study of the subject of research, we have involved empirical research of students of the Faculty of Education of the National University of Physical Education and Sports of Ukraine in a number of 136 (one hundred and thirty six) people. Among them, 45 are second-year students, 45 are thirdyear students and 46 are fourth-year students.

The definition of levels of development of abilities for self-regulation was determined, features of the motivational-value aspect of selfregulation (subjective control, motives of achievement and avoidance of failures, personality orientation) were analyzed, the procedural aspect of self-regulation of students was analyzed, the degree and level of selfassessment adequacy was determined and its relationship was established with motivational-value and procedural components of self-regulation. 


\section{Mospan Marina, Kovalchuk Victoria}

\section{Features of self-regulation in pedagogical activity}

First we will analyze the data of successful students. As you know, people are significantly different in how they tend to share responsibility for their own actions. The tendency of a person to attribute responsibility for the results of his activity caused by external circumstances or vice versa, his own efforts and abilities, psychologists call the localization of control or control locus.

The general indicator of internality was an indicator of the need for activity, determined the extent of its own initiative and autonomy in life, and demonstrated how much students regulated their lives. The obtained results showed that the need for these students is pronounced in successful students. An internal type of subjective control characterizes the sample, since deviations up to more than 5 are set on all 7 scales. The data also indicates that successful students have a high level of activity and responsibility for their lives. They believe that most of the important events in their lives were the result of their own actions; these actions are an important factor in their own career and in interpersonal relationships in the team. Respondents belonging to this group believe that their life depends mainly on personal efforts and abilities, they can successfully achieve their goals in the future and will prefer situations in which the responsibility for overcoming them will lie with them. Responsibility for negative events, failures, troubles, which appear in conflict situations of teaching activity, they take upon themselves.

The results obtained by the method of the subjective control locus give a generalized characteristic of the personality of the average student in conflict situations of pedagogical activity, associated with a high level of activity, independence, self-awareness, responsibility for what is happening. However, the results of internality, which were received on a scale of pedagogical (professional) relations, attract attention. This scale determines at what extent a person considers his actions to be an important factor in organizing the educational process, in relationships that exist in the team. The declared internality is 6.5 , which is lower than the figures on other scales. Although this indicator suggests that students are responsible for all the organizational components of professional activity, they really understand the limits of their own influence. From the theoretical analysis of the students' motivation and value sphere, one can assume that the motivation for achieving and motivation for avoiding failure in pedagogical activity will play a significant 
role in the development and formation of means of self-regulation. The research hypothesizes that successful students will have a certain correlation between the level of development of motives for achievement and the level of development of motives for avoiding failures.

The average value for motivation for success is $23.5 \%$, which corresponds to a moderately high level of motivation for success; the average value of the failure avoidance motivation is twice as high $-55.9 \%$. The research revealed that the tendency to succeed is a complex function of three variables: the motive for striving for success, the subjective probability of success, and its attractiveness in this situation. The motive for the pursuit of success is the persistent disposition of the individual to experience pride and pleasure in achieving success. The tendency to avoid failures is a multiplier function of the motive for avoiding failure (the desire to avoid failure and shame) and its attractiveness in a particular situation.

The predominance of one or another motivational trend affects the choice of the degree of complexity of the task. People with a predominant motive for the desire to succeed choose medium difficulty tasks, different from those in whom the prevailing motive for avoiding failures, which choose or very easy tasks (their choice guarantees success), or very difficult (if it can not solve the problems of this class, then do not get upset, because failure with tasks that few can handle, does not give grounds for shame and a sense of humiliation).

In order to establish the significance of the differences between types of motivation, we used the Student's t-test for dependent samples.

The domination of the motive of pursuit of success is seen in all manifestations of the student's personality. Students with a predominance of the motive for a desire for success, are inherent: perception of the situation of achievement as a necessary and habitual component of life; confidence in a successful outcome; active search for information about your successes; readiness to assume responsibility and determination in uncertain situations; choice of goals of medium or higher complexity, high intensity of desire for purpose; get more pleasure from interesting tasks; a desire to do more or less complicated work, but one that can really be fulfilled; the ability not to get lost in a competition or skill test; desire for reasonable risk; average, realistic level of aspirations; great dedication in the event of conflict situations; increase in claims after success and decline after failure; realistic, coherent planning, with a focus on the distant future. 


\section{Mospan Marina, Kovalchuk Victoria}

Consequently, this motive provides a high level of activity, prompting the person to look for new ways to realize their own energy, abilities and forces. Also, a high level of motivation for success is associated with the willingness to be responsible for the decisions, the ability to set goals and achieve them on their own, which was confirmed in the results of the study of the subjective control locus of students. It is clear that the revealed features of the motivational-value sphere contribute to the success of pedagogical activity.

Defining the determination of students allowed to identify the different priorities: the focus on the activity $-70.6 \%$; the focus on interaction $29,4 \%$, so most of them are focused on professional pedagogical activity and realization of its functions. From the results of our testing we found that students who more then others are successfully coping with the conflict situations of pedagogical activity, which means that professional activity is the most important for them. The above mentioned is at the basis of selfrealization of their mental stability. It was also found that students who have a more pronounced focus on themselves or on interaction, the focus on the case is in second place. For students who have a thrust on business, the focus is also on the result, the setting on quality and accuracy, the desire to best perform pedagogical tasks, the tendency to defend their point of view in conflict situations, the ability to cooperate, collaborate for the cause, and then orientation for direct reward, priority status, revaluation of status values, authoritarianism, aggressiveness, search for social approval, dependence on group thought, assessment, decision. The study of the characteristics of the students' target perspective revealed the following results: $94.1 \%$ of respondents have both common life goals and careers, and goals for the next five years, and goals for the coming year. 5.9\% of students did not indicate one of three target perspectives. The largest share in this was on the near target - in $70.6 \%$ of students, on average $-17.6 \%$ and on the distant - at $11.8 \%$. The study of the consistency of the temporal perspective of students suggests that: for $5.9 \%$ of the past, present, future is not related; for $94.1 \%$ - related. For the majority of the researchers, the most significant is the future and the present. Students concentrate their greatest efforts on the short-term - to support the current status and enhance it in future pedagogical activities.

The study of the consistency of the temporal perspective of students gave the following results: for $6.8 \%$ of the studied past, the present, the 
future is not related (all three circles were drawn separately from each other); for $93.2 \%$ of all, or two out of three perspectives were linked. By the size of the circle were represented as follows: the most significant past $-5,2 \%$; the most significant present $-15.4 \%$; the most significant future $-23.6 \%$; the most significant present and future $-33,1 \%$; equivalent to all three circles $-22.7 \%$.

According to the obtained indicators, for the majority of investigated the most significant are the future and the present. As you can see, the target perspective in most students is consistent, and they are sufficiently aware of the connection of future events with the past and the present. The representation of all three perspectives and their interconnectivity contributes to the fact that motives and goals fulfill their activating role, and actions in conflict situations are implemented effectively. In our study, it was found that students are concentrating their greatest efforts in the near term, which suggests that their perspectives are aimed at supporting the current status and its growth in the future. And although most scholars emphasize the importance of consistency, realism, and differentiation of the target perspective, we find different positions in relation to which orientation on which planning should be more pronounced. L.A. Kolesnichenko is close to our conclusions about the need for a more successful activity of greater clarity of the short-term perspective, which affects the support of the motive in an active state for achieving the goal [7, p. 440].

In the qualitative experiment, we studied the level of formation of a number of indicators of the motivational-value component of selfregulation. His results were divided into levels and constituents.

The distribution of students by components (indicators) of the motivational-value component of self-regulation was more or less homogeneous. For all components of self-regulation, the most pronounced was the high level of self-regulation. Such a result confirms the opinion that self-regulation in conflict situations of pedagogical activity plays a predominant role and ensures its success.

The study of the level of formation of the procedural component of selfregulation in students was aimed at determining the regulatory profile, which characterizes the individual level of development of the main regulatory mechanisms that provide the functional links of a coherent system of selfregulation. V.I. Morosanova distinguishes between two types of self-regulation profiles: harmonic ("smooth") - when all major processes are developed 


\section{Mospan Marina, Kovalchuk Victoria}

approximately equally and "accented" ("spiky") - when the regulatory links are characterized by different degrees of formation [9, p. 118].

The analysis of the data shows that there are three types of effective selfregulatory profiles for students. Effective level of self-regulation is achieved by students with a high level of development of the overwhelming majority of regulatory units; with approximately the same number of peaks of high and average level; with a presence in the profile of low-level indicators, with the mandatory presence of high-level indicators. We have practically not found profiles with a low level of development of all units. In general, low rates are very rare and are always close to the high and medium levels of development of other units. The results obtained by us give grounds to assert about the presence of the corresponding compensatory mechanisms in the processes of self-regulation of students in conflict situations of pedagogical activity.

Attention is drawn to the results obtained on the "independence" scale. As can be seen from Table. 3.6, in $23 \%$ of the studied indicators of independence are low, and only in $13.7 \%$ - at high, with high and average indicators of other parts of the profile of self-regulation. This function in the pedagogical activity of students is related to the extent of their influence on the process of professional activity, with the limits of their independence in it. Consequently, when developing certain plans and programs of pedagogical activity, they must necessarily understand the limit of their own independence in the system in which they are located. Therefore, as we see, in the self-regulation profile on the scale of autonomy the average indicators prevail. It seems to us that these indices coincide with the data on the scale of the internality of the subjective control locus in professional relations, where internality has somewhat lower rates than other scales.

The results obtained by us can be compared with the earlier theoretical assumptions made, namely: the development of these or other functions depends on the style of self-regulation, which a person chooses; the student must have not only one, but several effective methods of self-regulation, which are characterized by the ratio of "strong" and "weak" functions of selfregulation; The "weak" side of the regulation will be offset by the "strong".

As a result, we can conclude that there is simultaneous representation in a certain part of the investigated different levels of development of regulatory units (from low to high). At the same time, one can observe the common features of stylistic features of student self-regulation: the 
lack of low indicators of "planning" and "programming". A significant number of students is characterized by a harmonious ("smoothed") selfregulation profile in conflict situations, when all major functions are presented at a relatively high level. This gives us reason to assert that the high level of achievements in pedagogical activity and the requirements of self-regulation activity form a harmonious style with high indicators of all regulatory branches. Similar results were obtained by V. Morosanova in Russia and L. A. Kolesnichenko in Ukraine, which testifies in favor of our statement about the versatility of such a profile to achieve the peaks of professionalism.

Thus, students with a high level of professionalism are characterized by the practical absence of inefficient self-regulation profiles with a predominance of low and intermediate levels of regulatory links. In these students, there are two self-regulatory profiles: "smoothed" (with the high development of almost all self-regulatory functions) and "spiky" (with the simultaneous representation of average and high performance). In general, students are characterized by a high level of conscious planning and programming of their own activities, the adequacy of the evaluation of the results of actions, the absence of fixation of failures, high level of flexibility, rapid orientation in a conflict situation, stability and ability not to be lost in conditions of uncertainty, creativity in approaches to solving The treatment of atypical situations, the average level of autonomy, constant connections, persistence in achieving their own goals, the accuracy and timeliness of correcting their mistakes pedagogically activity.

In the qualifying experiment, we checked what role self-regulation plays in self-regulation of mental stability self-esteem. We needed to determine the level and adequacy of self-esteem in students who successfully cope with conflict situations in teaching activities. As a result of the testing, 53\% of the participants in the study found an adequate self-esteem and $47 \%$ adequate to the tendency to overestimate. The average value of adequate self-esteem was $59.2 \%$. The obtained results showed that for successful students, the characteristic is adequate and adequate to the tendency to overestimate self-esteem. Proceeding from the role of self-assessment in the process of formation of the ability to self-regulation, with the help of the coefficient Ch. Spirman, we tried to find a correlation between self-esteem and other content-procedural parameters of self-regulation. As a result, certain features of correlation of self-evaluation and other parameters of 


\section{Mospan Marina, Kovalchuk Victoria}

self-regulation were revealed: self-esteem has a direct relationship with the focus on oneself and the feedback with the focus on the matter and on the interaction; there is a positive correlation between self-esteem with motivation for achievement and negative with motivation to avoid failures; there is a positive correlation of self-esteem with the styles of selfregulation, namely, "modeling" and "planning".

However, in more detail, it was found that the established connection is ambiguous. During an additional comparative analysis of the mean values of these parameters, it was found that the focus on oneself is much higher in individuals with an adequate self-esteem with a tendency to overestimate. At the same time, the focus on the case is significantly higher for students with adequate self-esteem. The motivation to succeed is also significantly higher in individuals with adequate self-esteem, and the motivation to avoid failures is higher in individuals with an adequate self-esteem with a tendency to overstate, which is apparently due to fear not achieving the goal.

There were no significant differences in the stylistic peculiarities of individuals with adequate self-esteem and adequate to the tendency to exaggerate.

Thus, an adequate self-assessment is characterized by a greater focus on business and interaction, achievement motivation, "programming", "evaluation of results" and overall level of self-regulation. Proceeding from this, in order to ensure the successful self-regulation of the student's psychological stability in the conflict situations of pedagogical activity, it is necessary, first of all, to develop its adequate self-esteem.

The motivational-value aspect of self-regulation is characterized by a certain homogeneity of its indicators, the dominance of high levels. At the same time, the procedural aspect of self-regulation is not so homogeneous. The high level of indicators of the motivational-value component of self-regulation, along with self-assessment, plays a decisive role in the development of student self-regulation tools, but individually each of them cannot affect self-regulation in a definitive way.

The conclusions were verified in the process of comparative analysis of the indicators of successful and unsuccessful students. We evaluated the differences in a number of indicators: type of orientation, motivation, locus of control and self-esteem. The average values of the indicators, which were further compared with the t-criterion of the significance of the Student, were calculated. 
According to data on the content and procedural indicators of selfregulation of successful and unsuccessful students, significant differences were found in practically all indicators. Successful students characterize somewhat more business orientation, higher and adequate self-esteem, greater motivation for success, and less motivation to avoid failures. Regarding the control locus, successful students characterize greater internality with all parameters.

Data on the distribution of unsuccessful students by self-regulatory indicators indicate that the need for activity in most of the poorer students is poorly expressed; the motivation to succeed in almost half of the subjects is low, one third - at the average; motivation to avoid failures in almost half at a low level; differentiation of target perspective more than half of unsuccessful students is low; the near-term representation is almost $75 \%$ low; the consistency of the target perspective in almost one half of the subjects is low, one third is at an average level; the orientation of the person in half on the average level, one third in high and the fourth in the low level; self-esteem is almost half lower. Thus, low and middle level self-regulation is prevalent among unsuccessful students in almost all indicators.

We compared successful and unsuccessful students to integrative indicators of self-regulation. The comparison leads to the conclusion that the profile of unsuccessful students is predominantly low and intermediate. The indicated trends correlate with the data of statistical analysis, which confirmed the significance of the differences between successful and unsuccessful students. Integrative indicators give a generalized idea about the peculiarities of self-regulation formation in conflict situations of pedagogical activity in both groups of researchers, indicating the differences in the development of indicators of self-regulation of motivationalvalue and procedural aspects and self-esteem. Most of the unsuccessful students have an average and low level of development of indicators of the motivational-value component of self-regulation, indicating the need for their development. It is also necessary to raise in the direction of the adequacy of self-esteem of unsuccessful students. At a low level, the procedural aspect of self-regulation is presented in a small number of students. Here, the average level prevails. Thus, there are certain differences in the motivational-value and procedural components of self-regulation in successful and unsuccessful students. 


\section{Mospan Marina, Kovalchuk Victoria}

\section{Conflict situation in terms of educational work}

The level of self-direction in conflict situations has a proximate influence on the effectiveness of educational work. This interconnection integrates personal resistant dependence of students' activity results from the level of their mental, emotional, willing, personally professional features and from activity in general. The empirical study requires defining the criteria of the level of personal self-direction ability development in conflict situation in educational activity. It has studied the students' psychograms emphasizing on definition of those psychological components which are the most important for students' self-direction in conflict situations. It is specified that these characteristics are not functioning independently in general psychological system of activity, but they provide cumulative influence effect on educational process success in functional unity. It is defined that the development of students' self-direction modes has to start the formation of the motivational, value judgments mode, mental and cognitive mode. Analysis of received data demonstrates the existence of three types of selfdirection effective students' profile. The students who obtain the effective level of self-direction have a high - developed level of the majority of regulation links; with the existence of low-level indicators together with obligatory presence of high-level indicators. We haven't almost found out the profiles with low-level development of all links. Generally, low indicators are found out very rarely, and they always appear together with the high and average level of other links. Obtained results allow confirming the existence of appropriate compensational mechanism in students' selfdirection processes in conflict situations in terms of educational activity, as well as activity practical, emotional and willing component of readiness.

\section{Conclusions}

1. Analysis of scientific and methodological literature and the Internet has shown that the sports and pedagogical activity of the coach is connected with the necessity to perform complex multi-dimensional tasks (urgent decision-making, responsibility for the actions of others, improvement of work methods, solving of pedagogical and administrative issues, etc.) first of all leads to the emergence of mental emotional work load.

2.Psychological preconditions of professional activity of coaches that determine the emergence of emotional tension include external and internal stress factors; external: excessive number of obligations, lack 
of "vital energy", lack of time for relaxation, fear of being "thrown out of the cloth", subjective dissatisfaction with the working conditions, socio-demographic characteristics (age, pedagogical experience, work experience in a particular team, category, marital status); internal stress factors: motivation, needs and demands, goals and evaluation of their own activities. Individual personality traits that determine the professional burnout of coaches include introversion, high levels of emotional breadth and anxiety, high standards of behavior, as well as demonstrative and negative system of notions about people.

3. The effectiveness of the organization of the educational process and the process of professional formation of the teacher to a large extent determined by the level of development of his psychological mechanisms of self-regulation of voluntary activity.

4. Self-regulation of the voluntary activity of a person can be manifested in conscious and unconscious forms, at different levels, including personal level.Functional status of the teacher as the capacity for self-regulation, covering the following options: self-criticism to their own mental activity and its results; the capacity for self-government behavior; the ability to change patterns of behavior depending on changing circumstances and situations; level of mental stress; the possibility of overcoming unfavorable functional states.

5. The effective level of self-direction is achieved by the students with a high - developed level of the majority of regulation chains; with the approximately equal quantity of high- and average-scale picks; existence of low-level indicators together with obligatory presence of high-level indicators.

6. The organization of the pedagogical process and its results are in direct dependence on the personal and professional qualities of the individual.

7. The success of identifying the specific causes of the emergence of certain mental states in students depends on the validity of the analysis of their manifestations and the ability to solve the problem of emotional regulation of educational and cognitive activity.

8. The conducted psychogram allowed to highlight the significance of the following individual psychological components: motivation, the need for self-regulatory voluntary activity, personality activity, regulatory personality qualities, self-esteem, personality determination, level of anxiety. Development and formation of self-direction modes are the 


\section{Mospan Marina, Kovalchuk Victoria}

factors that define the demonstration of regularities and tendencies in this multidimensional system of connections. While defining the levels of self-direction ability development it has found out the peculiarities of motivational and axiological aspects of self-direction (subjective control, achievement motives and failure avoidance, personal direction). It has also been analyzed the processual aspect of students' self-regulation, it has been defined the rate and level of self-esteem adequacy and defined its connection with motivational, axiological and processual self-direction components.

9. Among the perspective directions of further exploration of this problem is further study: issues of arbitrary psychological self-regulation of teachers in conflict situations of pedagogical activity; issues related to the study of subjective determinants of professional reliability of teachers' activities.

\section{References:}

1. Bandurka A. (2000) Teoriya sotsial'nogo naucheniya [The theory of social science]. SPb.: Evraziya. (in Russian)

2. Berezhna Zh.V. (2013) Struktura profesijnoji pedaghoghichnoji dijaljnosti majbutnikh treneriv z plavannja [Structure of professional pedagogical activity of future swimming coaches] Spirituality of personality: methodology, theory and practice: Sb. sciences Works / Scientific Library of East Caucus. nats un-th them V. Dal. vol. 1, no 54, p. 21.

3. Boryshevsjkyj M.J. (1993) Rozvytok zdatnosti do samoreghuljaciji povedinky jak vyjav sub'jektnogho stanovlennja osobystosti [Development of the ability to self-regulation behavior as a manifestation of the subjective formation of the individual]. Kiev. (in Ukrainian)

4. Voronova V. I., V. Nikolajenko (2014) Trenersjkyj pidkhid do trenuvannja junykh futbolistiv [Trainer's podhid up to the trainings of young football players]. Theory and methodology of phisical vihovannya and sports, vol. 1, no. 1, p. 8.

5. Deminskiy A. Ts. (2005) Mnogoletnyaya sistema podgotovki sportsmena [The long-term system of preparation of the sportsman]. Khar'kov-Donetsk. (in Ukrainian)

6. Kedrovskiy B.G., Shalar O.G., Grinevich A.V. (2013) Vzaimoponimanie trenerov s yunymi sportsmenami [Mutual understanding of coaches with young athletes] Physical education of students, vol. № 4, no. 3, p. 31. (in Russian)

7. Kolesnichenko L.A. (2003) Psykhologhichna pidghotovka majbutnikh menedzheriv [Psychological preparation of future managers] Educational innovations and their influence on the quality of university education: Collection of materials of the scientific-methodical conference January 29. Ukrainian, Kiev, vol. № 1, no. 1, p. 440.

8. Konopkin O.A. (1995) Psikhicheskaya samoregulyatsiya proizvol'noy aktivnosti cheloveka (strukturno-funktsional'nyy aspekt) [Psychological self- 
regulation of arbitrary human activity (structural-functional aspect] Questions of psychology, vol. 1, no. 1, p. 5. (in Ukrainian)

9. Morosanova V.I., Konoz E.M. (2000) Stilevaya samoregulyatsiya povedeniya cheloveka [Styled self-regulation of human behavior] Questions of psychology, vol. 2, no. 1, p. 118. (in Russian)

10. Ogilvie, B.C., \& Howe, M. (1982). Career crisis in sport. In T. Orlick, J.T. Partington, \& J. H. Salmela (Eds.), Proceedings of the fifth World Congress of Sport Psychology. Coaching Association of Canada, p. 176. Ottawa.

11. Platonov V N. (2005) Sistema podgotovki sportsmenov v olimpiyskom sporte. Obshchaya teoriya i ee prakticheskie prilozheniya : uchebnik trenera vysshey kvalifikatsii [The system of training athletes in the Olympic sport. The general theory and its practical applications: the textbook of the trainer of the highest qualification] Moskov: Sovetskiy sport. (in Russian)

12. Prokhorov A.O. (2005) Funktsional'nye struktury i sredstva samoregulyatsii psikhicheskikh sostoyaniy [Functional structures and means of self-regulation of mental states] Psychological journal. vol. 25, no. 2, p. 68. (in Russian)

13. Stepanchenko N. I. (2012) Osoblyvosti profesijno-pedaghoghichnoji motyvaciji majbutnjogho sportyvnogho pedaghogha [Specializing in the professionalpedagogical motivation of the Maybutny sports teacher] Fiz. vihovannya, sports and culture of health at the time. casp-ve. vol. 3, p. 101. (in Ukrainian)

14. Tretjak O.S. (2002) Psykhichna samoreghuljacija v dijaljnosti uchytelja: ponjattja, sposoby, pryjomy [Mental self-regulation in the activity of the teacher: concepts, methods, techniques]. Current problems of psychology. Volume 1: Social Psychology. Psychology of management. Organizational psychology. K.: Institute of Psychology of G.S. Kostiuk, APS of Ukraine, (vol. 6), (pp. 235-242). (in Ukrainian)

15. Fedyk O.P. (1999) Psykhologhichni osoblyvosti profesijnoji pidghotovky studentiv do majbutnjoji sportyvno-pedaghoghichnoji dijaljnosti [Psychological peculiarities of professional preparation of students for the future of sports and pedagogical activity]. (PhD Thesis). Institute of Psychology them. GS Kostiuk, Kiev.

16. Chebykin O.Yu. (1992) Emotsional'noe regulirovanie uchebnovospitatel'noy deyatel'nosti [Emotional regulation of teaching and learning activities] Odessa. (in Ukrainian) 